\title{
The failure of methamphetamine hydrochloride to produce dissociation of
}

\section{an escape response}

\author{
TERRENCE P. CROWLEY and DAVID A. SISEMORE \\ University of Southern Mississippi, Hattiesburg, Miss. 39401
}

Twenty-seven albino rats were trained to make an escape response at one of two dosage levels of methamphetamine or in a placebo state. Subsequently, they were tested in both drug states, as well as in the nondrugged state, to determine if the conditioned response was associated with the specific drug condition of the organism during training. Virtually no dissociation was observed across different states. Animals trained at one dosage level responded in like fashion when tested at another dosage level and/or after an injection of physiological saline. Possible reasons for the lack of dissociation appeared to be the nature of the task and the minimal potential of methamphetamine to produce state-dependent conditioning.

Donald Overton (1964) conducted a series of experiments demonstrating that an escape response conditioned following relatively high doses of sodium pentobarbital would not transfer to the nondrugged state. The reverse was also found to be true. However, when the training drug conditions were reinstated, the response was again operable.

This phenomenon of "dissociated" or "state-dependent" conditioning has subsequently been demonstrated with chlorpromazine (Otis, 1964), chlordiazepoxide (Sachs, Weingarten, \& Klein, 1966), phenobarbital (Bindra \& Reichert, 1966), and alcohol (Strom \& Caird, 1967). More recently, Overton (1966) has demonstrated dissociation with several depressants and atropine-like drugs. Finally, response control of a $\mathrm{T}$-maze escape response has been obtained using nicotinic, antinicotinic, and antimuscarinic drugs (Overton, 1969). Dogs, rats, monkeys, cats, and humans have served as $S s$ in these demonstrations of state-dependent conditioning. Tasks involved in dissociative studies have ranged from performance on verbal learning material to simple escape responses. Overton (1968) has indicated the $\mathrm{T}$-maze escape response to be the most stringent index of significant dissociation.

Amphetamines have been reported to produce moderate dissociation of a conditioned avoidance response ( $\mathrm{Lal} \&$ Roffman, 1969). Belleville (1964) reported greater resistance to extinction of a barpressing response due to changes from amphetamine states in training to the placebo state during extinction.

The present study was designed to test the dissociative potential of methamphetamine hydrochloride ( $\mathrm{MH}$ ), using the stringency of a $\mathrm{T}$-maze escape response. Further, all necessary controls, as advised by Miller (1957), These controls were sometimes lacking in previous studies testing the dissociative value of amphetamines.

\section{SUBJECTS}

Thirty naive male albino rats of the Sprague-Dawley strain served as Ss. The rats were approximately 110 days old at the beginning of the experiment, and their body weights ranged from 320 to $380 \mathrm{~g}$ per animal. The Ss were maintained on an ad lib diet of Purina Lab Chow and were housed individually.

\section{APPARATUS}

A Hunter T-maze with $46-\mathrm{cm}$ arms and a $77-\mathrm{cm}$ runway was used. The grid floor of the maze was supplied with a constant power supply of $.08 \mathrm{~W}$ by a BRS shock scrambler (Model SGS-001). The $15-\mathrm{cm}$ area at the extremes of each arm of the T-maze served as end boxes. Only one of these end boxes was uncharged, and it served as the goalbox during training. During testing, both end boxes were free of electrical charge.

Solutions of $5 \mathrm{mg} / \mathrm{kg}$ and $1 \mathrm{mg} / \mathrm{kg}$ of $\mathrm{MH}$ (common/trade name: "Methedrine"1) made isotonic with sodium chloride served to produce the given in the form of a $.9 \%$ sodium chloride solution, and the volume of these injections was $1 \mathrm{cc} / \mathrm{kg}$. All injections were intraperitoneal. \section{PROCEDURE}

The present experiment consisted of two phases: a training phase and a testing phase. The Ss were assigned randomly to one of three training groups. Each training group contained 10 animals. The group trained on $5 \mathrm{mg} / \mathrm{kg}$ of $\mathrm{MH}$ was designated $1 \mathrm{mg} / \mathrm{kg}$ of $\mathrm{MH}$ was designated Group MH1. Finally, the group trained on isotonic saline was designated Group IS. were used in the present experiment. drugged states. Sham injections were Group MH5. The group trained on
Prior to training, each animals was given a $10-\mathrm{min}$ period to explore the T-maze and was subsequently trained to run to the arm opposite that of his original preference. Throughout both training and testing phases, each $S$ was given six trials per day, per injection. A response was considered correct when $S$ ran directly to the correct goalbox (not remaining in the runway longer than $60 \mathrm{sec}$ ) without breaking a photoelectric cell circuit at the entrance to the inappropriate arm of the maze.

\section{TRAINING}

In the training phase, each $\mathrm{S}$ in Group MH5 received a $5-\mathrm{mg} / \mathrm{kg}$ injection of $\mathrm{MH}$ and was then returned to its cage until the time elapsed $(1 \mathrm{~h})$ necessary for the drug to have optimal effect. Following this period, each animal was removed from its cage and dropped from a height of 6 in. onto the charged grid floor. Upon completion of the trial (running into the correct end box), each animal was immediately removed from the maze. The intertrial interval was approximately $30 \mathrm{sec}$. In the same manner, each $S$ in Group MH1 and Group IS was given a $1-\mathrm{mg} / \mathrm{kg}$ injection of $\mathrm{MH}$ and $\mathrm{a} 1-\mathrm{ml} / \mathrm{kg}$ injection of isotonic saline, respectively. Each animal in Group MH1 was then returned to its cage and remained there until the time elapsed $(40 \mathrm{~min})$ necessary for the drug to have optimal effect. Rats in Group IS were returned to their cages for $45 \mathrm{~min}$ before testing began. Following this period, each $S$ was removed from its cage and dropped from a height of 6 in. onto the charged grid floor. The criterion for trial completion and the intertrial interval for Groups $\mathrm{MH} 1$ and IS were the same as those for Group MH5.

Sessions began daily at approximately 1:00 p.m., and, although animals were run by groups, the order of injections was systematically varied both for Ss and groups. The desired response was considered to have been acquired when an animal made six correct responses during a single session.

$$
\text { TESTING }
$$

The day following the completion of training, each animal was introduced to a series of test trials. All three training groups were tested in the same manner; i.e., each $\mathrm{S}$ was given six test trials per day, per injection, for 6 successive days. An animal from each training group was assigned randomly to 1 of 10 counterbalanced dosage level sequences. This altemation of doses resulted in every S's receiving 12 test trials at each of the three dosage levels $(5 \mathrm{mg} / \mathrm{kg}$, $1 \mathrm{mg} / \mathrm{kg}$, and no drug).

The number of correct $T$-maze escape responses for each $\mathrm{S}$ on the 12 
Table 1

Mean Correct Responses for Each Training Group Under Test Conditions

Test Conditions

\begin{tabular}{lccc}
$\begin{array}{l}\text { Training } \\
\text { Groups }\end{array}$ & $\begin{array}{c}\text { Isotonic } \\
\text { Saline }\end{array}$ & $\begin{array}{c}1 \mathrm{mg} / \mathbf{k g} \\
\mathrm{MH}\end{array}$ & $\begin{array}{c}5 \mathrm{mg} / \mathbf{k g} \\
\mathrm{MH}\end{array}$ \\
\hline IS & 11.55 & 11.86 & 11.45 \\
MH1 & 11.20 & 11.60 & 10.90 \\
MH5 & 11.60 & 11.90 & 12.00 \\
\hline
\end{tabular}

test trials at each dosage level was compared both within and between groups to determine the extent of transfer from one dosage level to another.

\section{RESULTS}

Analysis of the data revealed no significant dissociation of the T-maze escape response following injections of $\mathrm{MH}$. Conditioning transferred from drugged to nondrugged states and from nondrugged to drugged states with virtually no decrement in response. In fact, additional statistical probes designed to uncover differences otherwise obscured by dosage sequence and time involved in testing revealed no significant lack of transfer between drugged states.

Since Hartley's $F_{\max }$ test (Pearson \& Hartley, 1954 ) revealed heterogeneity of variance between training groups, the results of the training procedures were analyzed using a Kruskal-Wallis one-way analysis of variance by ranks (Siegel, 1956). The results of this analysis indicated no significant difference in the number of ranked errors during the training phase between the three training groups.

Test trails were evaluated using a Lindquist Type I design (Lindquist, 1965). Neither main effect was significant at the .05 level. The Group by Drug interaction, crucial to a demonstration of dissociation, proved significant only at the .50 level. Variations in mean response rate before and after drug-state changes are reflected in Table 1.

The data were further analyzed by days and/or injection sequence. In no case did these calculated $t$ values exceed the .10 level of significance.

Three rats in Group MH5 failed to reach acquisition criterion and thus could not be tested for retention. All Ss in Group MH1 and Group IS reached acquisition criterion.

$$
\text { DISCUSSION }
$$

The results of the present study indicate virtually no decrement of response when the $S s$ were trained in one drug state and tested in either another drug state or in the nondrugged state. Several reasons might be proposed to explain this failure to find significant dissociation between drugged and nondrugged states using MH. First, it well may be that $\mathrm{MH}$ does not acquire response control in the same fashion or to the extent of sodium pentobarbital. Overton (1968) stated that the speed with which various drugs acquire response control probably indicates any potential that drug might have to produce dissociative conditioning. He had previously found that amphetamines acquire response control in a T-maze rather slowly. ${ }^{2}$ Harris \& Balster (1968), however, obtained relatively rapid response control in a barpressing situation controlled by the presence or absence of amphetamines. Such a discriminative task appears more sensitive to any possible amphetamine dissociative effect than a T-maze escape response.

If the dissociative phenomenon is viewed as a restriction of response generalization, a second possible explanation for the present lack of dissociation suggests itself. This mode of explanation holds that drugs producing dissociative conditioning are those that most completely limit generalization. Thus, although generalization may not have been complete under $\mathrm{MH}$, it could have been sufficient to determine the T-maze choice when no trained alternative was present in the otherwise naive rats.

Lastly, the differences in chemical composition of dl-amphetamine, which can produce response control (Harris \& Balster, 1968), and $\mathbf{M H}$, which did not produce dissociation, may be such that the former is capable of producing state-dependent conditioning, while the latter is not. A similar situation exists with crude curare, which produces dissociation (Girden \& Culler, 1937), and with the chemically related drug d-tubocurarine, which does not produce a response decrement from drugged to nondrugged state (Black, Carlson \& Solomon, 1962).

To appraise further any dissociative potential of $\mathrm{MH}$, an additional test of state dependency was made that was not originally planned. The three rats in Group MH5 that did not reach acquisition criterion in the 60 training trials were allowed to rest in their home cages for 10 successive days. Although these animals did not acquire the required escape response, they demonstrated a persistent tendency to run to the incorrect end box or to remain in the charged runway. After 10 days had elapsed, thereby correcting for possible incomplete biotransformation of the drug over a 24-h period, these animals were again introduced into the testing apparatus. On 3 successive days, these three animals were given 6 test trials following an injection of physiological saline. All three animals persisted in the above-mentioned fixated behavior. Only one animal made one correct response over this 18-trial retraining period. These findings suggest that state-dependent conditioning does not occur with $\mathrm{MH}$ in the present experimental situation.

The possibility still existed that the present failure to find significant dissociation may have been a function of confounding due to injection sequence and/or a performance increment across the 6 days of testing. To investigate this possibility, a series of six $t$ tests, designed to capitalize on any chance differences, was run (Lindquist, 1965). This statistical technique was deemed acceptable because hypothesis testing per se was not involved, but rather a probe attempting clarification of the findings. Further, if no significant differences were found using these tests, as was the case, then it could be concluded that little, if any, dissociation could be observed under the influence of $\mathrm{MH}$ using a design and task similar to that originally used by Overton (1964). The failure of any of these $t$ tests to be significant above the .10 level seems to indicate rather conclusively that $\mathrm{MH}$ does not produce dissociation using the stringency of a T-maze escape response.

\section{REFERENCES}

BELLEVILLE, R. E. Control of behavior by drug-produced internal stimuli. Psychopharmacologia, 1964, 5, 95-105.

BINDRA, D. \& REICHERT, H Dissociation of movement initiation without dissociation of response choice. Psychonomic Science, 1966, 4, 95-96.

BLACK. A. H., CARLSON, N. J., \& SOLOMON, R. L. Exploratory studies of the conditioning of autonomic responses in curarized dogs. Psychological Monographs, 1962, 76(29, Whole No. 548 ).

GIRDEN, E., \& CULLER, E. A. $C$ onditioned responses in curarized striated muscle in dogs. Journal of Comparative Psychology, 1937, 23, 261-274.

HARRIS, R. T.. \& BALSTER. R. L Discriminative control by dl-amphetamine and saline of lever choice and response patterning. Psychonomic Science, $1968,10,105-106$.

LAL, H., \& ROFFMAN, M. Learning associated with "amphetamine state." Reprinted from the Proceedings, 77th Annual Convention, APA, 1969, 881-882.

LINDQUIST. E. F. Design and analysis of experiments in psychology and education. Boston: Houghton Mifflin, 1965.

MILLER. N. E. Objective techniques for studying motivational effects of drugs on animals. In S. Garattini and V. Ghetti (Eds.), Psychotropic drugs. Amsterdam: Elsevier. 1957. Pp. 83-103.

OTIS, L. S. Dissociation and recovery of a response learned under the influence of chlorpromazine or saline. Science, 1964 , $143,1347-1348$

OVERTON. D. A. State-dependent or dissociated learning produced with 
pentobarbital. Joumal of Comparative \& Physiological Psychology, 1964, 1, 3-12 OVERTON, D. A. State-dependent learning produced by depressant and atropine-like drugs. Psychopharmacologia, 1966, 10, 6-31.

OVERTON. D. A. Dissociated learning in drug states (state-dependent learning). In D. H. Efronn et al (Eds.) Psychopharmacology: $A$ review of progress, 1957-1967. PHS Publication No. 1836 . Washington, D.C: U.S. Government Printing Office, 1968.

OVERTON, D. A. Control of T-maze choice by nicotinic, antinicotinic and antimuscarinic drugs. Proceedings, 77 th Annual Convention, APA, 1969 , 869-870.

PEARSON, E. S., \& HARTLEY. H. O. Biometrika: Tables for statisticians. Vol. I. Cambridge: University Press. 1954.

SACHS, E WEINGARTEN, M \& KLEIN, N. W., JR. Effects of chlordiazepoxide on the acquisition of avoidance leaming and its transfer to normal state and other drug conditions. Psychopharmacologia, 1966 , 9, 17-30.
SIEGEL, S. Nonparametric statistics for the behavioral sciences. New York: McGraw-Hill, 1956.

STROM, T., \& CAIRD, W. K. The effects of alcohol on serial verbal learning in chronic alcoholics. Psychonomic Science. $1967,9,43-44$.

NOTES

1. Methedrine was supplied compliments of Burroughs Wellcome \& Co., Tuckahoe, N.Y.

2. Donald A. Overton, personal communication, March 24, 1970. 